\title{
UtroUp is a novel six zinc finger artificial transcription factor that recognises 18 base pairs of the utrophin promoter and efficiently drives utrophin upregulation
}

\author{
Annalisa Onori ${ }^{1}$, Cinzia Pisani ${ }^{1}$, Georgios Strimpakos ${ }^{2}$, Lucia Monaco ${ }^{3}$, Elisabetta Mattei ${ }^{2}$, Claudio Passananti ${ }^{1}$ \\ and Nicoletta Corbi ${ }^{*}$
}

\begin{abstract}
Background: Duchenne muscular dystrophy (DMD) is the most common X-linked muscle degenerative disease and it is due to the absence of the cytoskeletal protein dystrophin. Currently there is no effective treatment for DMD. Among the different strategies for achieving a functional recovery of the dystrophic muscle, the upregulation of the dystrophin-related gene utrophin is becoming more and more feasible.

Results: We have previously shown that the zinc finger-based artificial transcriptional factor "Jazz" corrects the dystrophic pathology in mdx mice by upregulating utrophin gene expression. Here we describe a novel artificial transcription factor, named "UtroUp", engineered to further improve the DNA-binding specificity. UtroUp has been designed to recognise an extended DNA target sequence on both the human and mouse utrophin gene promoters. The UtroUp DNA-binding domain contains six zinc finger motifs in tandem, which is able to recognise an 18-base-pair DNA target sequence that statistically is present only once in the human genome. To achieve a higher transcriptional activation, we coupled the UtroUp DNA-binding domain with the innovative transcriptional activation domain, which was derived from the multivalent adaptor protein Che-1/AATF. We show that the artificial transcription factor UtroUp, due to its six zinc finger tandem motif, possesses a low dissociation constant that is consistent with a strong affinity/specificity toward its DNA-binding site. When expressed in mammalian cell lines, UtroUp promotes utrophin transcription and efficiently accesses active chromatin promoting accumulation of the acetylated form of histone $\mathrm{H} 3$ in the utrophin promoter locus.
\end{abstract}

Conclusions: This novel artificial molecule may represent an improved platform for the development of future applications in DMD treatment.

Keywords: DMD, Dystrophin, Utrophin, Zinc finger, Artificial transcription factor, Activation domain, Che-1/AATF

\section{Background}

Duchenne Muscular Dystrophy (DMD) is the most common X-linked degenerative muscle disease. The diagnostic marker for DMD is the absence of the cytoskeletal protein dystrophin, which plays a major structural role in muscle by providing stability to the sarcolemma during muscle contractions [1]. DMD still lacks an effective cure;

\footnotetext{
* Correspondence: nicoletta.corbi@libero.it

${ }^{1}$ Institute of Molecular Biology and Pathology CNR, c/o Department of Molecular Medicine, University "Sapienza”, Viale Regina Elena 291, 00161, Rome, Italy

Full list of author information is available at the end of the article
}

although different therapeutic strategies for DMD are currently being explored [2-6], a variety of drawbacks has significantly delayed their clinical translation. A promising approach for DMD therapy is based on increasing the levels of utrophin, a cytoskeletal protein that is similar to dystrophin and is able to compensate for its absence. Dystrophin and utrophin display a high degree of homology, and both bind members of the dystrophin-associated protein complex (DAPC) [7]. In adult muscle, utrophin is localised preferentially at the neuromuscular junction (NMJ) and myotendinous junctions, while dystrophin is 
localised along the entire length of the sarcolemma [8]. However, utrophin is also found along the sarcolemma in developing muscle, in regenerating muscle after injury and in mdx (dystrophin-deficient) skeletal muscle [9]. In DMD patients, utrophin is often upregulated, but this upregulation is not sufficient to prevent the progression of muscular dystrophy. Although the adenoviral delivery of utrophin in the mouse model of DMD $(m d x)$ and in the dystrophindeficient dog ameliorates the pathology, the huge size of the utrophin gene is a critical disadvantage [10]. Therefore, studies developing natural or synthetic small molecules that upregulate utrophin could accelerate the clinical translation process [11-17]. To obtain upregulation of utrophin, we have engineered artificial zinc finger-based transcription factors that are capable of binding and activating transcription from promoter "A" of both the human and mouse utrophin genes [18-23]. Zinc finger domains have been shown to be optimal building blocks for generating artificial transcription factors due to their versatility and modularity $[24,25]$. In particular, a "recognition code" that relates the amino acids of a single zinc finger to its associated DNA target has been utilised as a guide for the DNA binding design [24-30]. Changes in the key amino acid positions (-1, +3 and +6$)$ of the zinc finger alpha-helix alter the DNAbinding specificity of a zinc finger and enable it to bind the programmed DNA-binding site [24]. We generated transgenic mice that specifically over-express an artificial three zinc finger protein in the muscle, named "Jazz", which is able to specifically upregulate the utrophin gene [20]. Crossing the Jazz transgenic mice with the mouse $\mathrm{Du}-$ chenne muscular dystrophy mouse model " $m d x$ " results in a strong amelioration of the dystrophic phenotype [22,23]. In a continued attempt to improve the artificial transcription factor's DNA-binding affinity/specificity, we engineered "UtroUp" that recognises a longer DNA target sequence than its prototype gene Jazz. UtroUp has been designed to target the eighteen-base-pair DNA sequence present in both human and mouse utrophin gene promoters " $\mathrm{A}$ ". This target sequence is unique and conserved in both genomes. Here, we show that the artificial transcription factor UtroUp, due to its six zinc finger tandem motif, and its low dissociation constant $(\mathrm{Kd})$ possesses a strong affinity/specificity toward its DNA-binding site. UtroUp, coupled with its activation domain that was derived from the adaptor protein Che-1/AATF [21], efficiently accesses the active chromatin in the utrophin promoter locus and strongly activates utrophin transcription. This novel artificial molecule represents an improved platform for the development of future applications in the DMD gene therapy field.

\section{Methods}

Constructs

The synthesis of the UtroUp gene was performed by GenScript (New Jersey, USA). The company provided us with the gene cloned into the pUC57 vector at the EcoRI and XhoI restriction sites. We sub-cloned the synthetic gene into pGEX-4T1 bacterial expression vector (GSTUtroUp) and into the pRK5/myc mammalian expression vector, under the control of cytomegalovirus regulatory regions, in fusion with the $\mathrm{CJ} 7$ trans-activation domain (CJ7-UtroUp) [21]. CJ7-Jazz molecule was cloned in the same pRK5/myc mammalian expression vector. Note that here, we simply referred to $\mathrm{CJ} 7$ as the activation domain, which is one hundred amino acids long and strictly derived from the human Che-1/AATF protein, and not as the entire fusion protein that was described in our previous publication [21].

\section{Expression of the bacterial recombinant fusion proteins}

The recombinant GST-UtroUp protein and the recombinant GST-Jazz protein were expressed in BL21(DE3) host bacteria by an IPTG induction and were purified using glutathione Sepharose 4B beads as previously described [18]. The GST fusion proteins were separated by SDS-PAGE electrophoresis, visualized by Coomassie blue staining and quantified.

\section{Electrophoretic mobility shift assay (EMSA) and dissociation constant}

The EMSA were performed as previously described [18]. The oligonucleotide probes containing one copy of the WT UtroUp DNA target (underlined) were the following: forward primer 5'-A TTA AGC CGG GCT GCT GCG GGC TGG GAG TAT GAT CC-3' and reverse primer $5^{\prime}$ GG ATC ATA CTC CCA GCC CGC AGC AGC CCG GCT TAA T-3'. The mutagenized oligonucleotide probes were: "Mutated" UtroUp forward primer 5'-A TTA AGC CGG GCT GCT taa taa TGG GAG TAT GAT CC- $3^{\prime}$ and reverse primer $5^{\prime}$-GG ATC ATA CTC CCA tta tta AGC AGC CCG GCT TAA T-3'; "Scrambled" UtroUp forward primer 5'-A TTA AGC CGG ACA ACC ATC GAT GTC CGT TAT GAT CC- $3^{\prime}$ and reverse primer $5^{\prime}$-GG ATC ATA ACG GAC ATC GAT GGT TGT CCG GCT TAA $\mathrm{T}-3^{\prime}$. The oligos used in the EMSA were labelled by a T4 polynucleotide kinase. The binding buffer that was used contained $20 \mathrm{mM}$ Hepes pH 7.5, $0.5 \mathrm{mM}$ DTT, $100 \mathrm{mM}$ $\mathrm{NaCl}, 50 \mu \mathrm{M} \mathrm{ZnCl}_{2}, 50 \mu \mathrm{g} / \mathrm{ml} \mathrm{BSA}, 100 \mathrm{ng}$ of poly (dI$\mathrm{dC}), 0.05 \%$ NP40 and 5\% glycerol. Percentage of both inputs: WT and the " 6 base pair" mutated DNA target probes shifted at each protein concentration were quantified using ImageJ analysis software and plotted in a graph. To measure and compare the apparent dissociation constant (Kd) of the GST-UtroUp and GST-Jazz complexed with their DNA-target, we performed a series of EMSA with increasing amount of GST-UtroUp $(1,2,3,4,8,12$, 30, $60 \mathrm{nM}$ and $90 \mathrm{nM}$ ) or increasing amount of GST-Jazz $(5,8,16,32,64$ and $96 \mathrm{nM})$ incubated with a constant amount of labelled UtroUp-Jazz DNA target, following the 
procedure previously described [18]. Briefly, the radioactive signals were visualised by autoradiography and quantified by the ImageQuant software (Molecular Dynamics, Sunnyvale, CA) and the data were analysed with the KaleidaGraph programme (Abelbeck Software, Reading, PA). The Kd values were determined as an average of data as mean \pm S.D. of five separate experiments.

\section{Cell lines, transient transfections and reporter gene assay}

The human HeLa cell line was grown in Dulbecco's modified Eagle's medium (DMEM) (Gibco Corporation, Grand Island, NY, USA) supplemented with 10\% foetal calf serum. Transient transfection experiments in the HeLa cell line were carried out using Lipofectin and PLUS reagents (Life Technologies Corporation, Carlsbad, Ca.) according to the manufacturer's instructions. Cell extracts were prepared and assayed for luciferase (LUC) activity according to the manufacturer's instructions (Promega, Madison, WI, USA) using a Berthold LB9506 luminometer. The total protein in the extracts was quantified using a Bradford assay, and the LUC activity from equal amounts of protein was determined and normalised for beta-galactosidase activity.

\section{Chromatin immunoprecipitation assay (ChIP)}

Chromatin Immunoprecipitation was performed using a ChIP assay kit according to the manufacturer's instructions (Upstate Biotechnology, Charlottesville, VA, USA). Approximately 8 million cells were cross-linked with $1 \%$ formaldehyde for $10 \mathrm{~min}$ at $37^{\circ} \mathrm{C}$ and then lysed. The cell lysate was sonicated on ice, which resulted in DNA fragments of approximately $500 \mathrm{bp}$ in length. Equal amounts of chromatin from each sample were immunoprecipitated over night with either an anti-acetylated-Histone H3 rabbit polyclonal antibody (Upstate Biotechnology) or anti-myc 9E10 monoclonal antibody. DNA representing $0.005 \%$ of the sonicated chromatin solution (input) and $10 \%$ of the immunoprecipitated sonicated chromatin solution were amplified using the following primers: human utrophin promoter region primers forward $5^{\prime}$-CGGCA CGCACGGTTCACTCTGGAGCGC-3' and reverse $5^{\prime}$ CAGCAACTTTGTTCCGGAAGATCAGCC-3'; human thymidine kinase promoter region-specific primers forward 5'-GCCCCTTTAAACTTGGTGGGCGG-3' and reverse $5^{\prime}$-TTGCGCCTCCGGGAAGTTCACG-3'; human dystrophin promoter region-specific primers forward $5^{\prime}$ GTGTTTTAAGAATTGGCACCAG-3 ${ }^{\prime}$ and reverse $5^{\prime}$-A GTCTGAATAAGAGAAGCAGCA -3'; human chromosome 16 region-specific primers forward $5^{\prime}$-AGGACC ACTCGCTGGGTAAGCA-3' and reverse 5'-CGCGG AGGGTGACATGGGGT-3'; human chromosome 17 region-specific primers forward $5^{\prime}$-ACCTGTGTGTGG GTGGTGAGA-3' and reverse 5' ${ }^{\prime}$-CTGTAGGGCCCCA GGCACCAT-3'. The DNA sequence of the potential off- target site present in chromosome 16 is: $5^{\prime}$-GCTGCT GgGGGCTGGGgc-3', with 15/18 matches with UtroUp target sequence. The DNA sequence of the potential offtarget present in chromosome 17 is: $5^{\prime}$-GCTGCTGCG GGCTGGGga-3', with 16/18 matches with UtroUp Target sequence. The PCR conditions were the following: 30 cycles at $95^{\circ} \mathrm{C}$ for $45 \mathrm{~s}, 62^{\circ} \mathrm{C}$ for $30 \mathrm{~s}, 72^{\circ} \mathrm{C}$ for $30 \mathrm{~s}$ and a final extension at $72^{\circ} \mathrm{C}$ for $5 \mathrm{~min}$. Quantification of each chromatin immunoprecipitation (ChIP) experiment was performed using ImageJ software and plotted in a graph.

\section{RNA extraction, reverse transcriptase reaction and real-time PCR}

Total RNA was extracted from HeLa cells expressing either CJ7-UtroUp or the negative control pRK5 using the TRIzol reagent according to the manufacturer's instructions (Life Technologies). Two $\mu \mathrm{g}$ of RNA was reverse transcribed using oligo $(\mathrm{dT})_{12-18}$ primers and Superscript II (Life Technologies) in a final volume of $20 \mu \mathrm{l}$ at $42^{\circ} \mathrm{C}$ for $50 \mathrm{~min}$. A real-time PCR assay was performed in a 96-well format using the ABI Prism 7000 Sequence Detection System (Applied Biosystems, Foster City, CA). Primers and probes for utrophin (target gene) and for GAPDH (housekeeping gene) were purchased as TaqMan Gene Expression Assays (Applied Biosystems). PCR mixtures containing the cDNA template, the TaqMan Universal PCR master mix (Applied Biosystems) and the primers/probes in a final volume of $25 \mu \mathrm{l}$ were analysed in triplicate using the following conditions: an incubation at $50^{\circ} \mathrm{C}$ for $2 \mathrm{~min}$, denaturing at $95^{\circ} \mathrm{C}$ for $10 \mathrm{~min}$ and then 40 cycles of the amplification step at $95^{\circ} \mathrm{C}$ for $15 \mathrm{~s}$ and $60^{\circ} \mathrm{C}$ for $1 \mathrm{~min}$. For each gene amplification, a standard curve was generated using serial dilutions (200, $40,8,1.6$ and $0.32 \mathrm{ng}$ ) of cDNA from the HeLa cells (negative control). The results were analysed using the Applied Biosystems analysis software. The data are expressed as the ratio between utrophin and GAPDH mRNA expression.

\section{Western blot}

Proteins were extracted from HeLa cells using the following lysis buffer (50 mM Tris pH 7.4, $50 \mathrm{mM}$ EDTA, $250 \mathrm{mM} \mathrm{NaCl}, 50 \mathrm{mM} \mathrm{NaF}, 0.1 \%$ Triton X-100, 0.1 $\mathrm{mM} \mathrm{NaVO}$ and $0.5 \%$ glycerol) containing protease inhibitors. Equal amounts of total protein $(30-40 \mu \mathrm{g})$ were separated by SDS-PAGE electrophoresis, transferred to membranes and immunoblotted with the following antibodies: mouse monoclonal anti-myc 9E10, mouse monoclonal anti-alpha tubulin (Sigma Corporation, St. Louis, Missouri, USA), mouse monoclonal anti-utrophin (NOVOCASTRA, Newcastle, UK), rabbit polyclonal antilaminin (Sigma Corporation, St. Louis, Missouri, USA), mouse monoclonal anti-beta-Actin (Sigma Corporation, St. Louis, Missouri, USA), rabbit polyclonal anti-Sp1 (Santa 
Cruz, Santa Cruz, CA). Densitometric analysis of utrophin protein level was performed using ImageJ analysis software.

\section{Results and discussion}

One central point in the designing of synthetic zinc finger peptides is to increase their specificity toward the desired DNA target [25,31]. The simplest approach for success is to increase the length of the target sequence to decrease its frequency in the genome. By assuming a random base distribution, an 18-base-pair DNA target sequence is statistically predicted to be unique in the haploid human genome. We chose the following DNA target sequence: 5'- GCT GCT GCG GGC TGG GAG- 3', that is present only once in both human and mouse genomes, in the utrophin gene promoter "A" (Figure 1A). In order to target this 18-base-pair DNA sequence we designed and constructed a novel artificial gene named "UtroUp" containing six zinc finger domains in a tandem array. To be able to test the therapeutic potential of our artificial transcription factor in a dystrophic mouse model (mdx), we chose a DNA target sequence in a region that was completely conserved in both the human and the mouse utrophin promoter "A" (Figure 1A). This region is located near several natural transcription factor DNA- binding sites in a chromatin-accessible region [18]. UtroUp, with its six zinc finger domains, is an extended version of the previously engineered three zinc finger transcription factor Jazz [18,20-22]. At its $5^{\prime}$ end, the UtroUp DNA target sequence comprises 9 base pairs of the DNA target sequence of Jazz, as indicated in italics in Figure $1 \mathrm{~A}$ (right side). Figure $1 \mathrm{~B}$ shows the amino acid sequence of the UtroUp peptide. The first three UtroUp zinc fingers have been newly designed, engineered and selected, while the last three are coincident with the previously engineered Jazz zinc finger domains. The amino acids responsible for the specific nucleotide contact in each zinc finger (alpha helix, positions $-1,+3$ and +6) have been chosen on the basis of the available "recognition code" that combines the zinc finger primary structure and potential DNA-binding sites [18,24,28-30]. We have generated UtroUp by coupling the available recognition code with DNA binding performance selection evaluated by EMSA [18]. It is important to note that the zinc finger peptide binds the DNA target sequence in an anti-parallel manner. To test the UtroUp DNA-binding ability, we produced and purified UtroUp, which was fused to a glutathione S-transferase (GST) domain (GST-UtroUp), in bacteria (Figure 1C). The affinity/

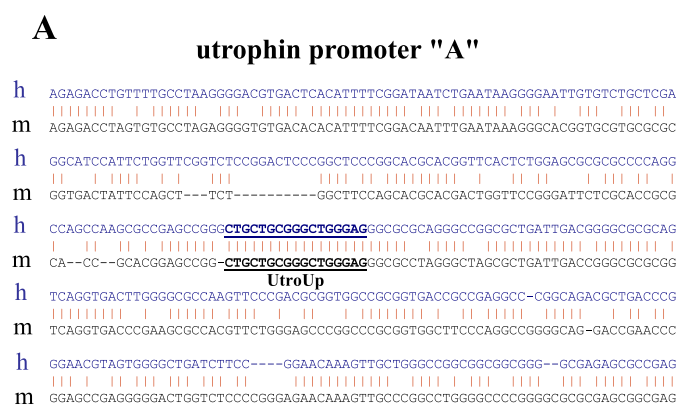

B

"UtroUp" zinc-finger domains

ILDRPYACPVESCDRRFSRSDNLVRHIRIHTG QKPFQCRICMRNFSRSDHLTTHNRTHTGEKPF ACDICGRKFADPGHLVRHNRIHTGEKPFACPV ESCDRRFSRSDELTRHIRIHTGQKPFQCRICM RNFS SRDVLRRHNRTHTGEKPFACDICGRKFA SRDVLRRHNRIHLRQNDLE

C

\author{
UtroUp \\ DNA binding target: \\ 5'-GCT-GCT-GCG-GGC-TGG-GAG- 3'
}

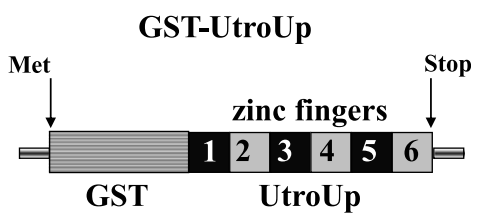

Figure 1 A graphical representation of the human and mouse utrophin promoters and the amino acid sequences of the six zinc finger UtroUp peptide (GenBank JQ073900). A: On the left is shown an alignment of DNA sequences of the human and mouse utrophin promoter " $A$ ". The UtroUp DNA target sequence, which is 18 base pairs long, is underlined. The DNA target sequence is 100\% conserved between humans and mice. On the right is shown the 18-base-pair UtroUp DNA target sequence. The portion of the Jazz DNA target sequence is indicated in italics. B: The amino acid sequence of the synthetic six zinc finger DNA-binding domain of the UtroUp peptide. Each zinc finger domain in the tandem array is underlined and numbered. The amino acid residues in the a-helix $(-1,+3$ and +6$)$, which are key for the DNA-binding specificity, are indicated in bold. The zinc finger domains 4, 5 and 6 are inherited by the Jazz peptide. C: A schematic representation of the bacterially produced UtroUp peptide fused to glutathione S-transferase (GST). 
specificity of GST-UtroUp toward its putative DNA target sequence was evaluated by electrophoretic mobility shift assays (EMSA).

As shown in Figure 2A a marked shift is observed when GST-UtroUp is incubated with the wild type (WT) oligonucleotide probe containing UtroUp DNA-binding site (lane 2), while no shift is revealed in presence of the "Scrambled" oligonucleotide probe (lane 4). Then, to test the overall binding activity of UtroUp, we concentrated on the DNA binding contribution of the two crucial central zinc fingers 3 and 4. We compared, in an EMSA assay, increasing amount of GST-UtroUp with either WT oligonucleotide target or centrally mutated oligonucleotide target. As shown in Figure 2B, a strong saturated shift signal is observed even at the lowest concentration of GSTUtroUp protein in the presence of the wild type oligonucleotide target (lanes 1-3), while the GST-UtroUp shift appears dramatically compromised in the presence of six base pairs mutated oligonucleotide DNA target (lanes 5-7) (see quantification analysis, Figure 2, panel B right). Importantly, comparing GST-UtroUp and GST-Jazz performance in the same EMSA, the DNA target shift in presence of GST-UtroUp is clearly stronger than the shift obtained with GST-Jazz (Figure 2C). Then, to measure the affinity of the GST-UtroUp toward its DNA target sequence, the dissociation constant $(\mathrm{Kd})$ was determined by EMSA performed

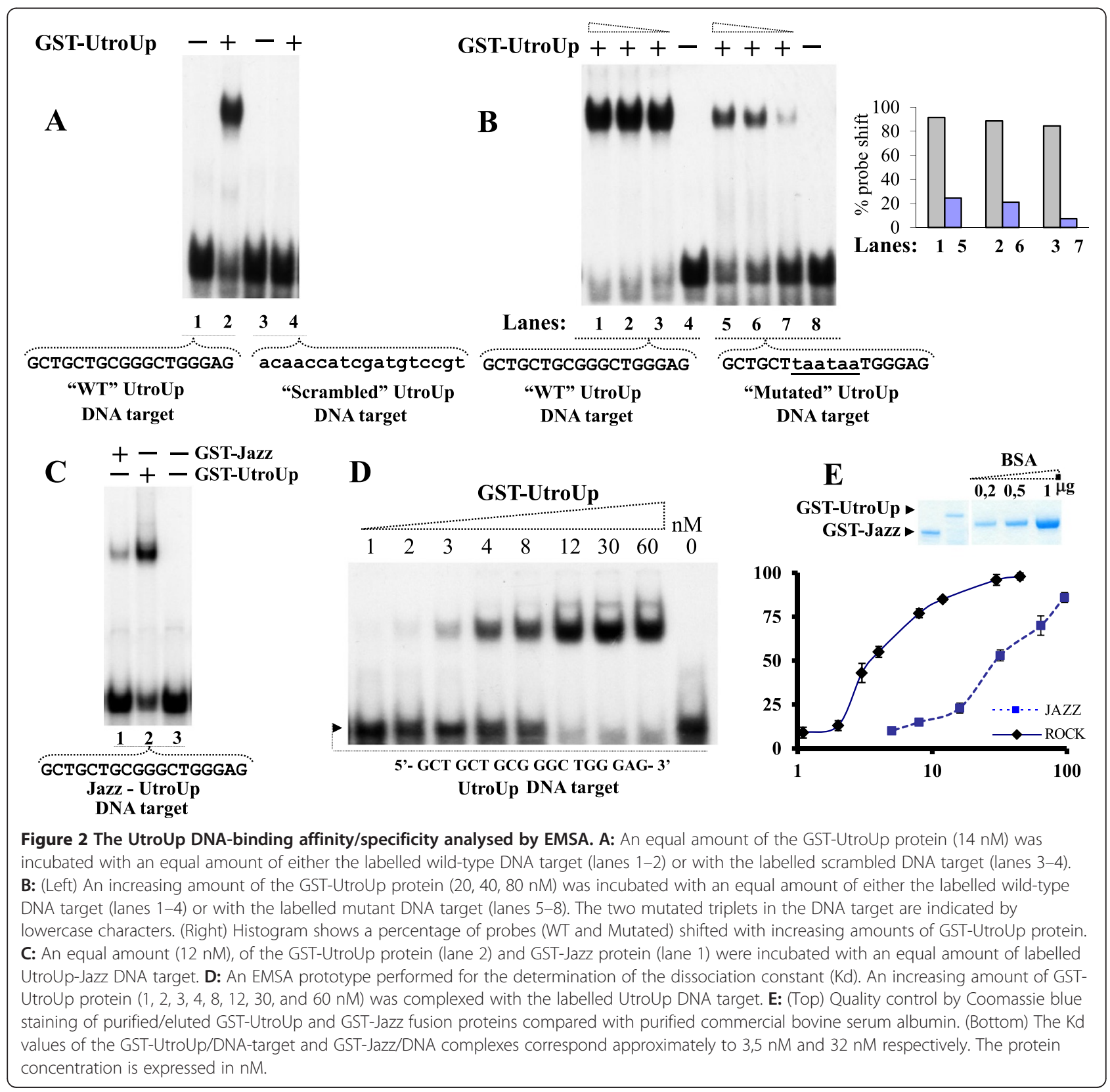


using increasing amounts of GST-UtroUp protein combined with a constant amount of labelled UtroUp DNA oligonucleotide target (Figure 2D). In our experimental conditions, we obtained for UtroUp a Kd of approximately 3,5 nM (Figure 2E). The UtroUp Kd value is lower than the $\mathrm{Kd}$ values measured for our artificial transcription factors that contain three or four zinc finger domains $[18,19]$, indicating a tighter binding of UtroUp to the DNA target sequence. In particular, UtroUp Kd value is about ten-fold lower than the Kd value of its progenitor Jazz (32nM), as shown in the EMSA derived graph in Figure 2E. Based on the encouraging UtroUp Kd data, we characterised the biological activity of UtroUp in the human HeLa cell line, as both a simple six zinc finger peptide (UtroUp) and as a fusion with the strong "CJ7" activation domain, which resulted in the CJ7-UtroUp molecule (Figure 3A) [21]. The CJ7 transcriptional activation domain was derived from the regulatory multivalent adaptor Che-1/AATF [3234]. The CJ7 domain is 100 amino acids in size, and it is a stronger activator than the canonical herpes simplex virusderived Vp16 activation domain [21]. We previously showed that the CJ7 domain in fusion with the synthetic three zinc finger Jazz protein efficiently promotes transcription and the accumulation of the acetylated form of histone $\mathrm{H} 3$ on the genomic utrophin promoter locus [21]. To evaluate the relative transcriptional activity of the CJ7UtroUp and the CJ7-Jazz artificial transcription factors [21], we separately transfected, into HeLa cells, the constructs expressing the two molecules and the construct expressing only the UtroUp zinc finger DNA binding domain (as a control) together with the luciferase reporter construct pXP-Luc [35], which contained the utrophin promoter "A" region including the 18-base-pair UtroUp target sequence (Figure 3B).

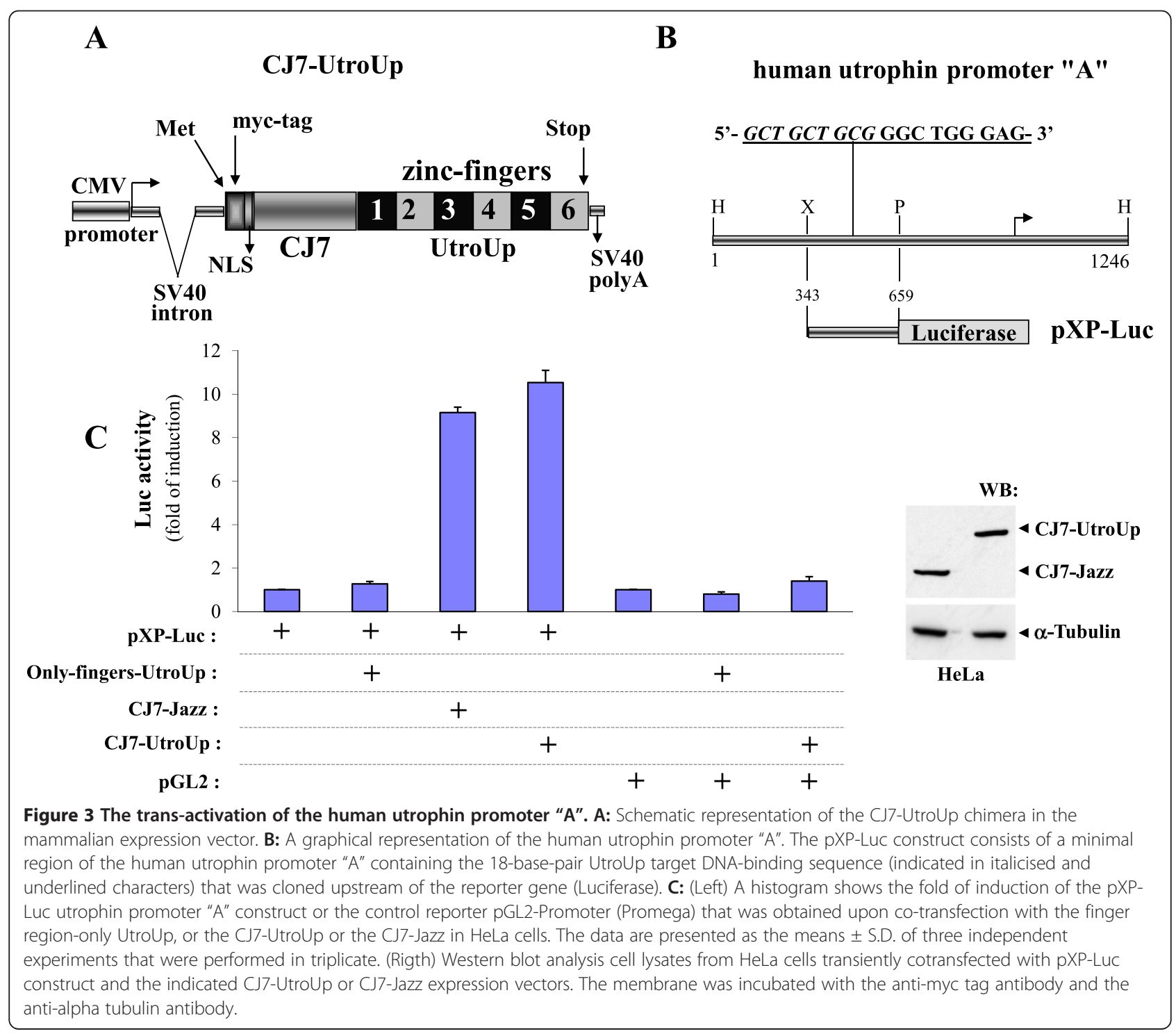


As shown in the histogram in Figure 3C, the analysis of the luciferase activity revealed a ten to eleven fold induction of the pXP-Luc construct in the presence of CJ7UtroUp. This strong activation appears to be highly specific, and it is even stronger than the activation obtained using the prototype CJ7-Jazz [21], taking into account a comparable expression of CJ7-UtroUp and CJ7-Jazz proteins, as shown in the western blot (Figure $3 \mathrm{C}$ ). To verify whether the six zinc finger protein CJ7-UtroUp accesses the utrophin promoter locus in the chromatin infrastructure, we performed chromatin immunoprecipitation experiments (ChIPs). As shown in Figure 4A, ChIP experiments demonstrated that CJ7-UtroUp accesses the genomic utrophin promoter $\mathrm{A}$ locus in an efficient way. To verify CJ7-UtroUp specificity toward the genomic utrophin promoter locus, we tested in the same ChIP experiments unrelated gene-promoters and potential UtroUp genomic "off-target" sites. A BLAST search indicated that the 18 base pairs UtroUp target sequence is present only once in both human and mouse genomes. As expected, the BLAST search pointed out several potential chromosomal off-target sites containing a number of nucleotide

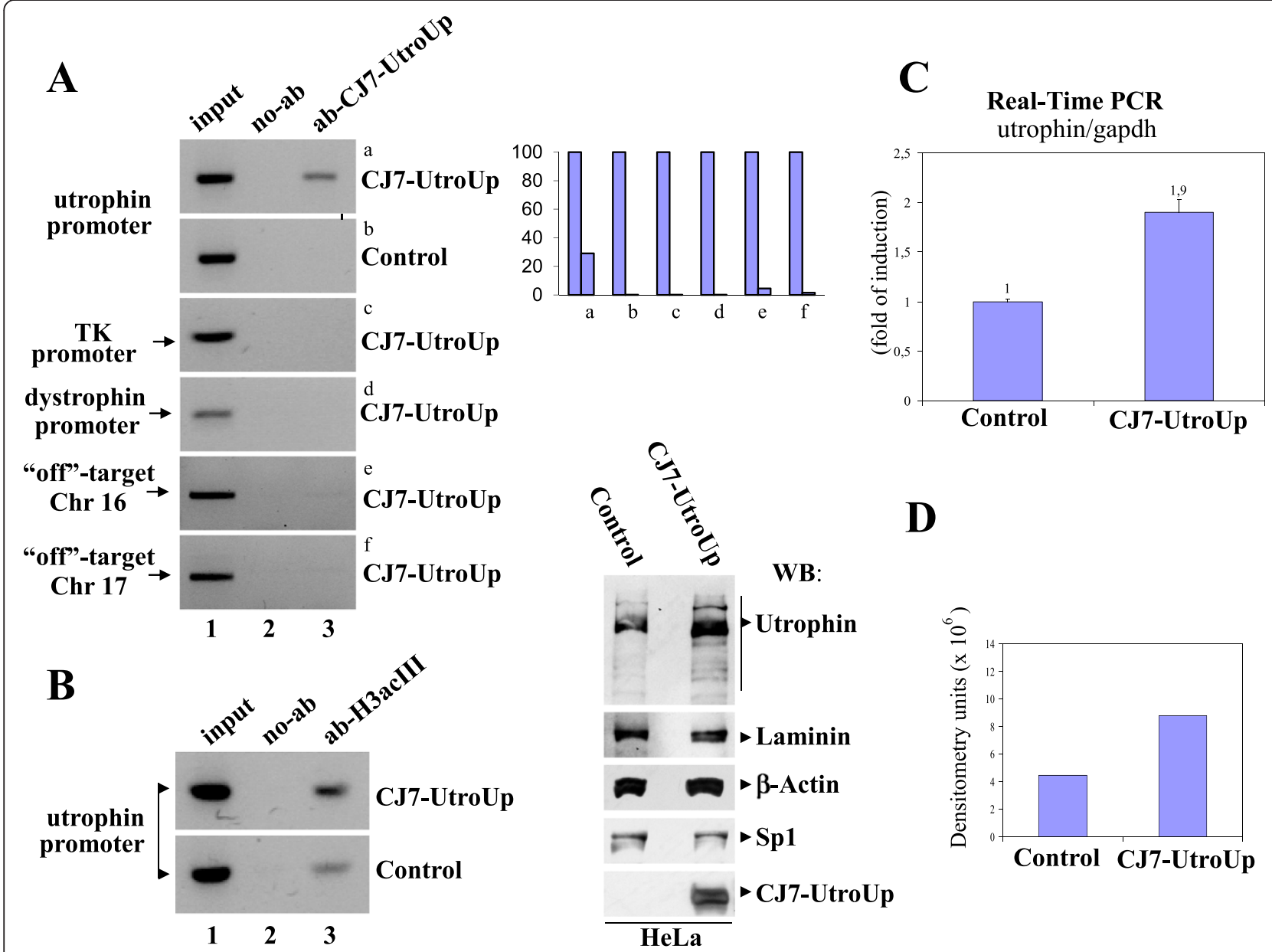

Figure 4 The binding and upregulation of the endogenous utrophin gene. A: (Left) The ChIP assay was performed in transfected HeLa cells (with either an empty control vector or with the CJ7-UtroUp expression vector) using myc-tag monoclonal antibody/protein G-agarose beads. The immunoprecipitates from each sample were analysed by PCR performed using primers specific for the human utrophin promoter " $A$ ". PCRs of the promoters of the unrelated thymidine kinase and dystrophin genes and PCRs of specific regions on the chromosomes 16 and 17 were included as controls. A sample representing the linear amplification of the total input chromatin (input) was included (lane 1). (Right) Histogram shows quantification of ChIP-PCR bands presented as fraction of the input. B: ChIP was performed in transfected HeLa cells (with either the CJ7UtroUp expression vector or with an empty control vector) using anti-acetylated histone $\mathrm{H} 3$ rabbit polyclonal antibody/protein $\mathrm{G}$-agarose beads. Immunoprecipitates from each sample were analyzed by PCR performed using primers specific for human utrophin promoter "A". C: The analysis by real-time PCR of the utrophin gene mRNA expression in HeLa cells transfected with the CJ7-UtroUp or control vectors. The ratio between the utrophin and GAPDH gene expression is shown as means \pm S.D. from three independent experiments that were performed in triplicate. D: (Left) Western blot analysis of total protein lysates from HeLa cells transfected with either empty vector (Control) or with the CJ7-UtroUp expression vector. The membrane was incubated with the indicated antibodies. (Right) Histogram shows utrophin expression evaluated by densitometric analysis. 
mismatches within the 18 base pairs UtroUp target sequence. In particular, we tested two potential off-target sites present in loci on human chromosome 16 and chromosome 17, carrying 15 base pair matches out of 18 and 16 base pair matches out of 18 respectively (see material and method section). A quantification analysis of all ChIP/PCR bands is reported in Figure 4A (right side). All these ChIP data taken together indicate a high specificity of CJ7-UtroUp protein toward its DNA target in the utrophin promoter A. Moreover as shown in Figure $4 \mathrm{~B}$ a ChIP assay demonstrated that CJ7-UtroUp is able to promote accumulation of the acetylated form of histone H3. Hyperacetylation correlates with transcriptional activation and indicates that histone-modifying activities [36,37] could contribute to the transcriptional control induced by CJ7UtroUp. Next, we determined the level of endogenous utrophin upregulation that was induced by the expression of CJ7-UtroUp. To this end, we performed a quantitative analysis of the utrophin mRNA levels using real-time PCR. As shown in Figure 4C, we observed an approximate 2.0-fold increase in utrophin transcription level in the presence of CJ7-UtroUp compared to the control sample. Additionally, to determine whether the changes in the utrophin mRNA expression levels, which were induced by the presence of CJ7-UtroUp, were consistent with changes in the utrophin protein level, we performed western blot analysis using an anti-utrophin antibody. As shown in Figure 4D, we observed a perfect correlation between the upregulation of the utrophin mRNA and the utrophin protein. In addition, CJ7-UtroUp appears to mimic the natural transcriptional regulatory mechanisms, which give rise to an increase in all of the different utrophin isoforms, as shown by the utrophin protein pattern in western blot.

The synthetic transcription factor Jazz [18], with its three zinc finger domains, binds a 9-base-pair DNA sequence. Bagly [19], the first Jazz variation, has four zinc finger domains and binds a 12-base-pair DNA sequence. As described here, UtroUp, with its six zinc finger domains, binds an 18-base-pair DNA sequence. Notably, a 9-base-pair DNA sequence is statistically present in the human genome $\left(\cong 3.5 \times 10^{9} \mathrm{bp}\right)$ approximately $1.3 \times 10^{4}$ times, a 12-base-pair sequence is present 210 times and an 18-base-pair sequence is present only once [31]. Moreover, when fused with our strong activation domain $\mathrm{CJ} 7$, UtroUp specifically and efficiently upregulates the utrophin gene expression.

\section{Conclusions}

In an attempt to improve the efficacy of our artificial transcription factors, engineered to reprogram the expression of the utrophin gene, we focused on tuning both DNAbinding affinity/specificity and transcriptional performances. Our novel artificial transcription factor, CJ7-
UtroUp, represents a good compromise between small size, high DNA target affinity/specificity and efficient transcriptional activation. The small size makes UtroUp particular suitable for viral vector delivery and the possibility of targeting a unique site in the genome extremely reduces off-target effects on global transcription. UtroUp and its upcoming variations may represent an important platform for the development of future applications in the DMD gene therapy field. Moreover, human myogenic cell lines and mouse models expressing UtroUp can offer an unique model system for screening novel compounds that are able to upregulate the utrophin gene for DMD treatment.

Importantly, our results contribute to demonstrate that artificial zinc finger transcription factors may be a class of therapeutic reagents for treatment of crucial inherited diseases [38].

\section{Abbreviations}

DMD: Duchenne Muscular Dystrophy; DAPC: Dystrophin-associated protein complex; NMJ: Neuromuscular junction; GST: Glutathione S-transferase; EMSA: Electrophoretic mobility shift assays; Kd: Dissociation constant; ChIP: Chromatin immunoprecipitation; BLAST: Basic Local Alignment Search Tool.

\section{Competing interests}

The authors declare that they have no competing interests.

\section{Authors' contributions}

$\mathrm{NC}$ and $\mathrm{CP}$ conceived and designed the experiments. $\mathrm{AO}, \mathrm{CiP}, \mathrm{NC}, \mathrm{CP}, \mathrm{GS}$, $L M$ and $E M$ performed the experiments. $A O, C i P, N C$ and $C P$ analyzed the data. NC and CP wrote the manuscript. All the authors read and approved the final manuscript.

\section{Acknowledgments}

This manuscript was edited for proper English language by American Journal Experts; Certificate Verification Key: C219-9C5A-B8C2-8EAF-792C. We thank Dr. R. G. Ruscitti for her valuable assistance. This work was supported by the Associazione Italiana per la Ricerca sul Cancro (AIRC) project IG 2009, by the Telethon project GGP10094, by the AFM project grant No 14353 and PRIN2008-81213. The UtroUp gene is the object of the following patents: CNR European patent $n^{\circ} 2193200$ and CNR Italian patent n 1868 RM 2007 A00523.

\section{Author details}

'Institute of Molecular Biology and Pathology CNR, c/o Department of Molecular Medicine, University "Sapienza”, Viale Regina Elena 291, 00161, Rome, Italy. ${ }^{2}$ Institute of Cell Biology and Neurobiology CNR, IRCCS Fondazione Santa Lucia, Via del Fosso di Fiorano 64, 00143, Rome, Italy. ${ }^{3}$ Department of Physiology and Pharmacology, University Sapienza, Piazzale Aldo Moro 5, 00185, Rome, Italy.

Received: 30 March 2012 Accepted: 12 December 2012

Published: 30 January 2013

\section{References}

1. McNally EM, Pytel P: Muscle Disease: The Muscular Dystrophies. Annu Rev Pathol Mech Dis 2007, 2:87-109.

2. Fairclough RJ, Bareja A, Davies KE: Progress in therapy for Duchenne muscular dystrophy. Exp Physiol 2011, 96(11):1101-1113.

3. Pichavant C, Aartsma-Rus A, Clemens PR, Davies KE, Dickson G, et al: Current status of pharmaceutical and genetic therapeutic approaches to treat DMD. Mol Ther 2011, 19(5):830-840.

4. Goyenvalle A, Seto JT, Davies KE, Chamberlain J: Therapeutic approaches to muscular dystrophy. Hum Mol Genet 2011, 20(R1):R69-78. 
5. Meng J, Muntoni F, Morgan JE: Stem cells to treat muscular dystrophies where are we? Neuromuscul Disord 2011, 21(1):4-12.

6. Cossu G, Sampaolesi M: New therapies for Duchenne muscular dystrophy: challenges, prospects and clinical trials. Trends Mol Med 2007, 13(12): 520-526.

7. Blake DJ, Weir A, Newey SE, Davies KE: Function and genetics of dystrophin and dystrophin-related proteins in muscle. Physiol Rev 2002, 82:291-329.

8. Ohlendieck K, Ervasti JM, Matsumura K, Kahl SD, Leveille CJ, et al: Dystrophin-related protein is localized to neuromuscular junctions of adult skeletal muscle. Neuron 1991, 7:499-508.

9. Gramolino AO, Karpati G, Jasmin BJ: Discordant expression of utrophin and its transcript in human and mouse skeletal muscles. J Neuropathol Exp Neurol 1999, 58:235-244.

10. Nowak KJ, Davies KE: Duchenne muscular dystrophy and dystrophin: pathogenesis and opportunities for treatment. EMBO Rep 2004, 5(9):872-876.

11. Khurana T, Davies KE: Pharmacological strategies for muscular dystrophy. Nat Rev Drug Discov 2003, 2:379-390.

12. Miura $P$, Jasmin BJ: Utrophin upregulation for treating Duchenne or Becker muscular dystrophy: how close are we? Trends Mol Med 2006, 3:122-129.

13. Stocksley MA, Chakkalakal JV, Bradford A, Miura P, De Repentigny Y, et al: A $1.3 \mathrm{~kb}$ promoter fragment confers spatial and temporal expression of utrophin A mRNA in mouse skeletal muscle fibers. Neuromuscul Disord 2005, 15(6):437-449.

14. Basu U, Gyrd-Hansen M, Baby SM, Lozynska O, Krag TO, et al: Heregulininduced epigenetic regulation of the utrophin-A promoter. FEBS Lett 2007, 4;581(22):4153-4158.

15. Perkins KJ, Basu U, Budak MT, Ketterer C, Baby SM, et al: Ets-2 repressor factor silences extrasynaptic utrophin by $\mathrm{N}$-box mediated repression in skeletal muscle. Mol Biol Cell 2007, 18(8):2864-2872.

16. Tinsley JM, Fairclough RJ, Storer R, Wilkes FJ, Potter AC, et al: Daily treatment with SMTC1100, a novel small molecule utrophin upregulator, dramatically reduces the dystrophic symptoms in the $\mathrm{mdx}$ mouse. PLOS One 2011, 6(5):e19189.

17. Amenta AR, Yilmaz A, Bogdanovich S, McKechnie BA, Abedi M, et al: Biglycan recruits utrophin to the sarcolemma and counters dystrophic pathology in mdx mice. Proc Natl Acad Sci U S A 2011, 108(2):762-767.

18. Corbi N, Libri V, Fanciulli M, Tinsley JM, Davies KE, Passananti C: The artificial zinc finger coding gene 'Jazz' binds the utrophin promoter and activates transcription. Gene Ther 2000, 7:1076-1083.

19. Onori A, Desantis A, Buontempo S, Di Certo MG, Fanciulli M, et al: The artificial 4-zinc-finger Bagly binds human utrophin promoter $A$ at the endogenous chromosomal site and activates transcription. Biochem Cell Biol 2007, 85(3):358-365.

20. Mattei E, Corbi N, Di Certo MG, Strimpakos G, Severini C, et al: Utrophin up-regulation by an artificial transcription factor in transgenic mice. PLOS One 2007, 22; 2(1):e774.

21. Desantis A, Onori A, Di Certo MG, Mattei E, Fanciulli M, et al: Novel activation domain derived from Che-1 cofactor coupled with the artificial protein Jazz drives utrophin upregulation. Neuromuscul Disord 2009, 2:158-162.

22. Di Certo MG, Corbi N, Strimpakos G, Onori A, Luvisetto S, et al: The artificial gene Jazz, a transcriptional regulator of utrophin, corrects the dystrophic pathology in mdx mice. Hum Mol Genet 2010, 19(5):752-760.

23. Passananti C, Corbi N, Onori A, Di Certo MG, Mattei E: Transgenic mice expressing an artificial zinc finger regulator targeting an endogenous gene. Methods Mol Biol 2010, 649:183-206.

24. Corbi N, Libri V, Onori A, Passananti C: Synthetic zinc finger peptides: old and novel applications. Biochem Cell Biol 2004, 82:428-36.

25. Klug A: The discovery of zinc fingers and their development for practical applications in gene regulation and genome manipulation. Q Rev Biophys 2010, 43(1):1-21.

26. ChooY K: A: Physical basis of a protein-DNA recognition code. Curr Opin Struct Biol 1997, 7(1):117-125.

27. Pabo CO, Peisach E, Grant RA: Design and selection of novel Cys2His2 zinc finger proteins. Annu Rev Biochem 2001, 70:313-340.

28. Segal DJ, Barbas CF 3rd: Custom DNA-binding proteins come of age: polydactyl zinc-finger proteins. Curr Opin Biotechnol 2001, 12(6):632-637.

29. Klug $A$ : The discovery of zinc fingers and their applications in gene regulation and genome manipulation. Annu Rev Biochem 2010, 79:213-31.
30. Bhakta MS, Segal DJ: The generation of zinc finger proteins by modular assembly. Methods Mol Biol 2010, 649:3-30.

31. Sera T: Zinc-finger-based artificial transcription factors and their applications. Adv Drug Deliv Rev 2009, 61(7-8):513-526.

32. Fanciulli M, Bruno T, Di Padova M, De Angelis $R$, lezzi $S$, lacobini $C$, et al: Identification of a novel partner of RNA polymerase II subunit 11, Che-1, which interacts with and affects the growth suppression function of $\mathrm{Rb}$. FASEB J 2000, 14(7):904-912.

33. Passananti C, Floridi A, Fanciulli M: Che-1/AATF, a multivalent adaptor connecting transcriptional regulation, checkpoint control, and apoptosis. Biochem Cell Biol 2007, 85(4):477-83.

34. Passananti C, Fanciulli M: The anti-apoptotic factor Che-1/AATF links transcriptional regulation, cell cycle control, and DNA damage response. Cell Div 2007, 16(2):21.

35. Dennis CL, Tinsley JM, Deconinck AE, Davies KE: Molecular and functional analysis of the utrophin promoter. Nucleic Acids Res 1996, 24:1646-1652.

36. Verschure PJ, Visser AE, Rots MG: Step out of the groove: epigenetic gene control systems and engineered transcription factors. Adv Genet 2006, 56:163-204.

37. Beltran AS, Blancafort P: Remodeling genomes with artificial transcription factors (ATFs). Methods Mol Biol 2010, 649:163-182.

38. Costa FC, Fedosyuk H, Neades R, de Los Rios JB, Peterson KR, Barbas CF 3rd: Induction of Fetal Hemoglobin In Vivo Mediated by a Synthetic $\gamma$-Globin Zinc Finger Activator. Anemia 2012, 2012:507894. doi:10.1155/2012/507894.

doi:10.1186/1471-2199-14-3

Cite this article as: Onori et al:: Utroup is a novel six zinc finger artificial transcription factor that recognises 18 base pairs of the utrophin promoter and efficiently drives utrophin upregulation. BMC Molecular Biology 2013 14:3.

\section{Submit your next manuscript to BioMed Central and take full advantage of:}

- Convenient online submission

- Thorough peer review

- No space constraints or color figure charges

- Immediate publication on acceptance

- Inclusion in PubMed, CAS, Scopus and Google Scholar

- Research which is freely available for redistribution

Submit your manuscript at www.biomedcentral.com/submit
C BioMed Central 